\title{
Religion, spirituality and mental health: results from a national study of English households
}

\author{
Michael King, Louise Marston, Sally McManus, Terry Brugha, Howard Meltzer \\ and Paul Bebbington
}

\section{Background}

Religious participation or belief may predict better mental health but most research is American and measures of spirituality are often conflated with well-being.

\section{Aims}

To examine associations between a spiritual or religious understanding of life and psychiatric symptoms and diagnoses.

\section{Method}

We analysed data collected from interviews with 7403 people who participated in the third National Psychiatric Morbidity Study in England.

\section{Results}

Of the participants $35 \%$ had a religious understanding of life, $19 \%$ were spiritual but not religious and $46 \%$ were neither religious nor spiritual. Religious people were similar to those who were neither religious nor spiritual with regard to the prevalence of mental disorders, except that the former were less likely to have ever used drugs (odds ratio $(O R)=0.73$, $95 \% \mathrm{Cl} 0.60-0.88$ ) or be a hazardous drinker ( $\mathrm{OR}=0.81,95 \%$ $\mathrm{Cl}$ 0.69-0.96). Spiritual people were more likely than those who were neither religious nor spiritual to have ever used $(\mathrm{OR}=1.24,95 \% \mathrm{Cl} 1.02-1.49)$ or be dependent on drugs $(\mathrm{OR}=1.77,95 \% \mathrm{Cl} 1.20-2.61)$, and to have abnormal eating attitudes $(\mathrm{OR}=1.46,95 \% \mathrm{Cl} 1.10-1.94)$, generalised anxiety disorder $(\mathrm{OR}=1.50,95 \% \mathrm{Cl} 1.09-2.06)$, any phobia $(\mathrm{OR}=1.72$, $95 \% \mathrm{Cl} 1.07-2.77$ ) or any neurotic disorder (OR $=1.37,95 \% \mathrm{Cl}$ 1.12-1.68). They were also more likely to be taking psychotropic medication $(\mathrm{OR}=1.40,95 \% \mathrm{Cl} 1.05-1.86)$.

\section{Conclusions}

People who have a spiritual understanding of life in the absence of a religious framework are vulnerable to mental disorder.

\section{Declaration of interest}

None.
It is often reported that, even after taking account of other influences, such as age, gender and social support, people who report religious belief and practice experience better mental and physical health than those who do not. ${ }^{1-3}$ However, in a metaanalysis of 147 studies on religious belief and depression, Smith et al found only a weak negative correlation $(-0.096)$ between religiousness and depressive symptoms. ${ }^{4}$ On average, positive religiousness accounted for only $1 \%$ of the variance in the severity of depressive symptoms. Furthermore, extrinsic religious orientation and so-called negative religious coping (for example, avoiding difficulties through religious activities, blaming God for difficulties) were associated with higher levels of depressive symptoms.

The way religiosity is measured in research can be problematic, particularly when well-being is included as a component of the measure itself. ${ }^{5}$ Furthermore, most research into this association has entailed Judeo-Christian concepts of religion in White, North American populations, and has seldom taken account of spiritual beliefs unconnected with personal or public religious practice. ${ }^{6}$ In a number of studies in the UK, we have reported that religious and spiritual beliefs are not linked to better physical health outcomes ${ }^{7,8}$ and, in particular that spiritual beliefs in the absence of a religious framework may be associated with poorer mental health. ${ }^{9}$ The third National Psychiatric Morbidity Survey in England ${ }^{10}$ was the first general population survey in this country to include questions on religious and spiritual beliefs. In this study we aimed to examine the association between such beliefs and receipt of psychiatric treatment, and a range of psychiatric symptoms and diagnoses in a random sample of the English population.

\section{Method}

\section{Survey methods}

The third National Psychiatric Morbidity Study was conducted between October 2006 and December 2007 across England, using individual or groups of postcode sectors as sampling units. ${ }^{10}$ In the first stage of sampling, postcode sectors were divided into regions based on strategic health authority. All the sampling units within each strategic health authority were further stratified on the basis of the proportion of people in non-manual classes, and sorted by the proportion of households without a car based on UK 2001 Census data. A total of 519 postal sectors were selected by sampling from each stratum with a probability proportional to size in terms of the number of delivery points. In the second stage of sampling, 28 delivery points were randomly selected within each of the selected postal sectors, providing a sample of 14532 delivery points. Interviewers visited the addresses to identify private households containing at least one person aged 16 or over. When visited, 1318 of the selected addresses were found not to contain a private household and were excluded from the survey sample. After contact was made with each eligible household, one person was randomly selected to take part, using the Kish method. ${ }^{11}$ Ethical constraints meant that data on people refusing to participate could not be collected. Trained interviewers conducted a structured, laptop computerised interview in respondents' homes, or elsewhere if requested, each interview lasting on average $90 \mathrm{~min}$. Interviewers were fully briefed on the administration of the survey, and followed full sets of written instructions. Topics covered on 1-day survey-specific 
training included introducing the survey, questionnaire content, confidentiality and respondent distress.

The survey data were weighted to take account of likelihood of selection and non-response, so that the results were representative of the English household population aged 16 years and over. Sample weights were first applied to take account of the different probabilities of selecting respondents in different sized households. Second, to reduce household non-response bias, a household-level weight was calculated from a logistic regression model using interviewer observation and area-level variables (collected from Census 2001 data) available for responding and non-responding households. Finally, calibration weighting based on age, gender and region weighted the data to represent the structure of the national population, and take account of differential non-response between regions and age $\times$ gender groups.

We focus on the weighted results in the text, but provide both weighted and unweighted bases in the table showing sociodemographics and life views (online Table DS1). The unweighted bases are presented where appropriate to show the number of respondents included. The weighted base shows the relative size of the various sample elements after weighting, reflecting their proportions in the English population. The absolute size of the weighted base has no particular significance, since it has been scaled to the achieved sample size. ${ }^{10}$

\section{Measures}

Following confirmation of demographic data, the following standardised instruments were used.

(a) Six questions adapted from those in the questionnaire version of the Royal Free interview for religious and spiritual beliefs, which assesses the nature and strength of beliefs and practice. $^{12,13}$ Because of the length of the overall interview, questions on each topic had to be kept as brief as possible. Participants were provided with the statement: 'By religion, we mean the actual practice of a faith, e.g. going to a temple, mosque, church or synagogue. Some people do not follow a religion but do have spiritual beliefs or experiences. Some people make sense of their lives without any religious or spiritual belief'. Although slightly shorter than in the Royal Free Interview, the words used are exactly the same, in order not to lose the statement's essential meaning or threatening the validity of the original instrument. The interview then went on: 'Would you say that you have a religious or spiritual understanding of your life?' Participants could indicate whether their understanding was predominately (i) religious; (ii) spiritual or (iii) neither. If they had a specific religion, they were asked to name it. If religious or spiritual, they were asked to indicate on two sliding scales of zero to ten how strongly they held to their understanding of life and how important practice of their faith (for example private meditation, religious services) was to them. These respondents were also asked to report how often they attended services, prayer meetings or places of worship.

(b) The revised Clinical Interview Schedule (CIS-R) collects data on symptoms of common mental disorder and derives psychiatric diagnoses according ICD-10. ${ }^{14-16}$ The CIS-R enquires about the presence and severity of 14 non-psychotic psychiatric symptoms during the week prior to interview. The CIS-R score may be analysed as: (i) a continuous score, along a single continuum of severity; (ii) a dichotomous variable (case threshold $\geqslant 12$ ); and (iii) ICD-10 diagnostic categories. ${ }^{15,17}$ Diagnostic algorithms for use with the CIS-R cover (i) depressive episodes (classified as mild, moderate or severe); (ii) four types of anxiety disorder, namely generalised anxiety disorder, panic disorder, phobias (classified as agoraphobia, social phobia and simple phobia), obsessivecompulsive disorder (OCD); and (iii) mixed anxiety/ depressive disorder. The latter include those who scored above the case threshold on the CIS-R, but do not meet diagnostic criteria for any other ICD-10 disorder.

(c) The Psychosis Screening Questionnaire (PSQ) is a brief schedule that screens for symptoms commonly found in psychotic disorders. ${ }^{18}$ Rather than making a definitive diagnosis, it indicates whether a psychotic disorder may be present.

(d) A shortened version of the Close Persons Questionnaire that evaluates social support. ${ }^{19}$ This had been used in previous national surveys. ${ }^{9,17}$ Seven questions enquire about the level of intimacy and social support from close friends and family. The answers are scored from one to three and are summed to a total score; higher scores indicate higher social support.

(e) The Alcohol Use Disorders Identification Test (AUDIT) questionnaire is a widely used and well validated instrument that contains 10 questions about use of, and attitudes to, alcohol consumption, in this instance over the preceding 12 months. ${ }^{20,21}$ Men who scored more than seven and women who scored more than four were classified as hazardous drinkers.

(f) The Trauma Screening Questionnaire (TSQ) ${ }^{22}$ was used to collect information on the presence of trauma-related symptoms in the past week. A traumatic event is one in which a person experiences, witnesses or is confronted with a death or a serious injury or threat to self or close others. It is more severe than a stressful life event. Scoring positively on this questionnaire indicates the presence of traumarelated symptoms in the preceding week and that a clinical assessment for post-traumatic stress disorder (PTSD) is warranted; it does not specify a diagnosis of PTSD, in particular because it evaluates only two of the four criteria taken to identify a traumatising event. As a screening tool it has high sensitivity and specificity but lower positive predictive value $(0.48)$ as a result of the usually low prevalence of PTSD (1\%) in most populations. ${ }^{22}$

(g) The SCOFF is a five-item screening tool for anorexia and bulimia nervosa that enquires about eating attitudes and behaviour over the preceding year. ${ }^{23}$ Endorsement of two or more items represented a positive screening for an eating disorder. A further question ('in the last year . . . did your feelings about food interfere with your ability to work, meet personal responsibilities, and/or enjoy a social life?') was added to judge the impact of such eating attitudes and behaviour.

(h) Problem gambling is gambling to a degree that compromises, disrupts or damages family, personal or recreational pursuits. This categorisation was based on the DSM-IV ${ }^{24}$ criteria for problem and pathological gambling. Participants who met three or more of these diagnostic criteria were classified as problem gamblers.

(i) Questions on use of recreational drugs came from the Diagnostic Interview Schedule. ${ }^{25}$ Use of a drug in the past year and the presence of one of five symptoms were used to indicate drug dependence. Dependence was categorised as dependence on cannabis only and dependence on other drugs (with or without cannabis dependence).

(j) One question explored how happy the participants felt ranging from very, to fairly and not too happy.

(k) Finally, one binary variable summarised whether or not the respondent was taking any form of psychotropic medication 
and one summarised whether or not they were receiving any form of psychotherapy or counselling.

\section{Statistical analysis}

All analyses were conducted in Stata release 12.0, for Windows, using the survey command to account for the unequal probability of selection and to adjust the standard errors to account for clustering in areas sampled in data collection. Our main analyses concerned possible associations between holding a religious, spiritual or secular life view and: receiving counselling/ psychotherapy or psychotropic medication for a mental disorder; mental disorders classified by the CIS-R; possible PTSD, psychosis or an eating disorder; hazardous drinking; recreational drug use and dependence; and level of happiness.

We explored these associations using logistic regression, except for happiness, which utilised ordered logistic regression and for drug dependence where multinomial logistic regression was used. We adjusted for gender, age group, ethnicity, educational attainment, marital status or perceived social support if they were significantly associated with the given outcome. Social support is known to be associated with religious belief and practice. ${ }^{26,27}$ The reference group chosen for these analyses were participants reporting a secular (neither religious nor spiritual) life view, given it was the largest and most distinct of the three groups in terms of absence of any spiritual belief.

\section{Results}

\section{Response rates and description of the population}

A total of $9 \%$ of sampled addresses contained no private households and $4 \%$ were addresses of unknown eligibility. This left a known eligible sample of 12694 addresses. Applying the eligibility rate among those where it was established, to those where it was not, it was estimated that $91 \%$ of those of unknown eligibility would have been eligible to take part. This increased the set sample of households to 13171 . In total, 7403 respondents $(56.2 \%)$ provided a productive interview. The mean age of the participants was 46.3 years (s.e. $=0.28$, unweighted range 16-97), 4206 (51.4\%) were women, $85 \%$ were White British, $26 \%$ had no educational qualifications and 52\% were married (online Table DS1).

\section{Understanding of life}

Of the participants 35\% had a religious understanding of life, 19\% were spiritual (without religious participation) and $46 \%$ were neither religious nor spiritual in outlook (online Table DS1). In total $53 \%$ gave a nominal religious affiliation, with the majority citing Christianity (86\%). Demographic characteristics of the sample stratified by understanding of life are shown in Table 1 . People with no religious or spiritual understanding were significantly younger and more often White British, but were less likely to have qualifications beyond secondary school or to be married. Religious people had stronger beliefs and placed more importance on practice of those beliefs than people with a purely spiritual understanding (Table 1).

\section{Mental disorders and substance use}

People with a religious understanding of life were less likely to use or be dependent on drugs, or be hazardous drinkers (Table 2). People with a spiritual understanding of life were more likely to have abnormal eating attitudes and any neurotic disorder. There

\begin{tabular}{|c|c|c|c|c|}
\hline Characteristics & Neither religious or spiritual & Spiritual & Religious & $P$ \\
\hline Male, \% & 55 & 44 & 43 & $<0.001$ \\
\hline Age, years: \% & & & & $<0.001$ \\
\hline $16-24$ & 19 & 11 & 10 & \\
\hline $25-34$ & 19 & 16 & 13 & \\
\hline $35-44$ & 20 & 21 & 17 & \\
\hline $45-54$ & 16 & 18 & 16 & \\
\hline $55-64$ & 13 & 17 & 17 & \\
\hline $65-74$ & 7 & 10 & 14 & \\
\hline $75+$ & 5 & 8 & 14 & \\
\hline Ethnicity, \% & & & & $<0.001$ \\
\hline White British & 93 & 86 & 74 & \\
\hline White non-British & 4 & 6 & 6 & \\
\hline Black & 1 & 3 & 6 & \\
\hline South Asian & 1 & 2 & 9 & \\
\hline Mixed or Other & 2 & 3 & 4 & \\
\hline Education, \% & & & & $<0.001$ \\
\hline No qualifications & 25 & 21 & 30 & \\
\hline School or foreign qualifications & 51 & 46 & 39 & \\
\hline Post-school qualifications & 24 & 32 & 30 & \\
\hline Civil status, $\%$ & & & & $<0.001$ \\
\hline Married & 46 & 53 & 60 & \\
\hline Cohabiting & 13 & 12 & 6 & \\
\hline Single & 28 & 21 & 17 & \\
\hline Widowed & 5 & 6 & 10 & \\
\hline Divorced & 6 & 7 & 5 & \\
\hline Separated & 2 & 2 & 2 & \\
\hline Social support, mean & 20.0 & 20.2 & 20.3 & $<0.001$ \\
\hline Strength of religious understanding, mean ${ }^{\mathrm{a}}$ & & 6.2 & 7.0 & $<0.001$ \\
\hline Importance of religious practice, mean ${ }^{\mathrm{a}}$ & & 4.4 & 6.2 & $<0.001$ \\
\hline
\end{tabular}


were no differences in overall happiness or level of social support. People with no religious or spiritual understanding were least likely to be taking psychotropic medication.

\section{Comparison of groups after adjustment for other influences}

In a multivariate regression, we selected those people with neither a religious nor spiritual understanding of life (the largest group) to serve as a reference against which to compare the other two groups, namely those with a religious understanding and those with a spiritual understanding of life. After adjustment for important associated influences, there were few substantial differences in prevalence of mental disorder or receipt of treatment between people with no religious or spiritual understanding and those who were religious, except for less drug use and hazardous drinking in the latter (Table 3). However, people with a spiritual understanding were more likely than those who were neither religious nor spiritual to take psychotropic medication, to use recreational drugs or be dependent on them, to have a generalised anxiety disorder, phobia or any neurotic disorder or to have abnormal eating attitudes.

\section{Discussion}

\section{Main findings}

Our main finding is that people who had a spiritual understanding of life had worse mental health than those with an understanding that was neither religious nor spiritual. Those who were religious were broadly similar, in terms of prevalence of mental disorder and use of mental health treatments, to those who were neither religious nor spiritual after adjustment for potential confounders, except they were significantly less likely to use, or be dependent on, drugs or alcohol. This supports evidence from a national UK sample of people from a range of Black and minority ethnic groups ${ }^{9}$ on the vulnerability of people who describe themselves as spiritual. It adds to the evidence that people with a spiritual understanding in the absence of a religious framework appear to have the worst mental health. It also confirms that religious people are less likely to use alcohol ${ }^{28}$ and recreational drugs ${ }^{29}$ but fails to confirm North American evidence that holding a religious understanding of life provides protection against mental disorders. ${ }^{30}$ It also concurs with other evidence from England that there is no clear relationship between religiosity and happiness. ${ }^{31}$

\section{Strengths and limitations}

The strengths of this study are the random selection of a nationally representative sample of participants, the sample size, an in-depth assessment of mental health and the use of standardised questions on religion and spirituality that were developed and standardised in the UK and do not overlap with questions on well-being. However, there are also a number of limitations. First, our results depend on the definitions of religion and spirituality that were posed to participants. Although spirituality is notoriously difficult to define, ${ }^{32}$ this way of describing it to research participants has at least been shown to be reliable. ${ }^{12,13}$ However, we did not examine religious belief in detail, nor to what extent it was intrinsic or extrinsic. ${ }^{33}$ Second, the cross-sectional nature of the data means

Table 2 Univariable associations with life view: outcomes $(n=7403)$

\begin{tabular}{|c|c|c|c|c|}
\hline & \multicolumn{3}{|c|}{$\%$} & \multirow[b]{2}{*}{$P$} \\
\hline & Neither religious or spiritual & Spiritual & Religious & \\
\hline \multicolumn{5}{|l|}{ Drug use } \\
\hline Ever used drugs & 32 & 30 & 16 & $<0.001$ \\
\hline Used any drug in the past year & 12 & 11 & 5 & $<0.001$ \\
\hline Drug dependent & 4 & 5 & 2 & $<0.001$ \\
\hline Dependent on cannabis & 3 & 4 & 1 & $<0.001$ \\
\hline Dependent on another drug (+/- cannabis) & 1 & 1 & 1 & \\
\hline Hazardous drinker & 30 & 23 & 17 & $<0.001$ \\
\hline Problem gambling & 0.8 & 0.6 & 0.7 & 0.880 \\
\hline Post-traumatic stress disorder & 3 & 3 & 3 & 0.527 \\
\hline \multicolumn{5}{|l|}{ Eating attitudes } \\
\hline SCOFF $\geqslant 2$ & 7 & 9 & 5 & 0.001 \\
\hline SCOFF score $\geqslant 2$ and food interferes with life ${ }^{a}$ & 2 & 2 & 1 & 0.646 \\
\hline \multicolumn{5}{|l|}{ Psychosis Screening Questionnaire } \\
\hline Definitely psychotic & 0.1 & 0.4 & 0.4 & 0.106 \\
\hline Probably psychotic & 0.3 & 0.6 & 0.5 & 0.118 \\
\hline \multicolumn{5}{|l|}{ Clinical Interview Schedule } \\
\hline Panic disorder & 1 & 1 & 1 & 0.618 \\
\hline Generalised anxiety disorder & 4 & 5 & 4 & 0.079 \\
\hline Mixed anxiety/depressive disorder & 8 & 10 & 8 & 0.154 \\
\hline Obsessive-compulsive disorder & 1 & 1 & 0.8 & 0.127 \\
\hline Any phobia & 2 & 3 & 2 & 0.055 \\
\hline Depression & 3 & 3 & 2 & 0.057 \\
\hline Any neurotic disorder & 16 & 19 & 15 & 0.011 \\
\hline Happiness & & & & 0.764 \\
\hline Very happy & 39 & 39 & 40 & \\
\hline Fairly happy & 53 & 52 & 52 & \\
\hline Not too happy & 8 & 9 & 8 & \\
\hline Receiving pharmacological treatment & 5 & 7 & 6 & 0.026 \\
\hline Receiving counselling/therapy & 3 & 3 & 2 & 0.360 \\
\hline
\end{tabular}




\begin{tabular}{|c|c|c|c|}
\hline \multirow[b]{2}{*}{ Outcome } & \multirow[b]{2}{*}{$n$} & \multicolumn{2}{|c|}{ OR $(95 \% \mathrm{Cl})$} \\
\hline & & Spiritual $^{\mathrm{b}}$ & Religious (+/- spiritual) $)^{\mathrm{b}}$ \\
\hline \multicolumn{4}{|l|}{ Drug use } \\
\hline Ever used drugs & 7166 & $1.24(1.02-1.49)$ & $0.73(0.60-0.88)$ \\
\hline Used any drug in the past year & 7298 & $1.38(1.06-1.81)$ & $0.64(0.47-0.87)$ \\
\hline Drug dependent & 7173 & $1.77(1.20-2.61)$ & $0.68(0.43-1.09)$ \\
\hline Dependent on cannabis ${ }^{c}$ & 7173 & $1.86(1.18-2.91)$ & $0.46(0.25-0.84)$ \\
\hline Dependent on other drugs (+/- cannabis) & & $1.55(0.78-3.11)$ & $1.34(0.66-2.74)$ \\
\hline Gambler & 6890 & $0.95(0.33-2.69)$ & $1.00(0.44-2.27)$ \\
\hline Post-traumatic stress disorder & 7036 & $1.24(0.81-1.88)$ & $1.22(0.85-1.76)$ \\
\hline \multicolumn{4}{|l|}{ Eating attitudes } \\
\hline SCOFF $\geqslant 2$ and food interferes with life & 7298 & $1.01(0.58-1.76)$ & $1.10(0.66-1.85)$ \\
\hline SCOFF $\geqslant 2$ & 7302 & $1.46(1.10-1.94)$ & $1.00(0.78-1.28)$ \\
\hline \multicolumn{4}{|l|}{ Clinical Interview Schedule } \\
\hline Panic & 7325 & $1.33(0.71-2.47)$ & $1.41(0.81-2.45)$ \\
\hline Generalised anxiety disorder & 7203 & $1.50(1.09-2.06)$ & $1.29(0.97-1.70)$ \\
\hline Mixed anxiety/depressive disorder & 7203 & $1.26(0.98-1.62)$ & $1.04(0.84-1.30)$ \\
\hline Obsessive-compulsive disorder & 7203 & $1.11(0.60-2.04)$ & $0.87(0.48-1.58)$ \\
\hline Any phobia & 7203 & $1.72(1.07-2.77)$ & $1.26(0.84-1.90)$ \\
\hline Depression & 7203 & $1.05(0.72-1.51)$ & $0.80(0.57-1.13)$ \\
\hline Any neurotic disorder & 7203 & $1.37(1.12-1.68)$ & $1.14(0.94-1.37)$ \\
\hline Hazardous drinker & 7315 & $0.93(0.78-1.11)$ & $0.81(0.69-0.96)$ \\
\hline Happiness & 7192 & $1.01(0.87-1.18)$ & $0.95(0.84-1.08)$ \\
\hline Receiving psychotropic treatment & 7175 & $1.40(1.05-1.86)$ & $1.18(0.89-1.56)$ \\
\hline Receiving counselling or therapy & 7325 & $1.15(0.77-1.73)$ & $1.00(0.68-1.47)$ \\
\hline
\end{tabular}

that we cannot attribute cause and effect to any relationship between spiritual beliefs and mental health.

\section{Comparison with findings from other studies}

A recent large USA internet survey of people who regarded themselves as non-religious ${ }^{34}$ also reported that non-religious people who held spiritual beliefs (only $2 \%$ of the survey population) had less emotional stability as measured by a personality rating scale. However, it is difficult to know how far we can compare such people with our spiritual group, which made up $19 \%$ of the study population. Although the authors concluded that belief is a measure of negative personality traits, their findings (and ours) are in opposition to earlier evidence from the UK that spirituality is associated with greater extraversion and optimism (rather than neuroticism and psychoticism), particularly among men. ${ }^{35}$ The limitation of the latter study, however was that it was based on a volunteer student population and is therefore unlikely to be generalisable. Another possible explanation for our finding concerning people with a spiritual life view is that they are caught up in an existential search that is driven by their emotional distress. ${ }^{9,36}$

Why might findings in Europe concerning the emotional stability of religious people vary from those in the USA? There is considerable evidence that the UK is a less religious country than the USA in terms of the number of people professing a belief in God or attending places of worship. ${ }^{37}$ We found that a relatively low number of people expressed some sort of spiritual or religious belief in this survey (54\%) in comparison with that found in recent surveys both in the UK and around the world where levels have been closer to $70 \% .{ }^{38,39}$ Given that religious participation in English society is a minority activity, it may be that the social support intrinsic to a more religious society is missing. A further possibility is the way in which we measured spiritual and religious understanding. The Royal Free Interview for Religious and Spiritual Beliefs was developed and standardised in the UK and has not been used extensively in the USA. However, this is not strictly a limitation as one could argue that instruments should be most appropriate to the setting in which they were developed. Certainly, the difference in the findings concerning religion and mental health between the USA and the UK would bear greater investigation.

We conclude that there is increasing evidence that people who profess spiritual beliefs in the absence of a religious framework are more vulnerable to mental disorder. The nature of this association needs greater examination in qualitative and in prospective quantitative research.

Michael King, MD, PhD, FRCP, FRCGP, FRCPsych, Unit of Mental Health Sciences, Faculty of Brain Sciences, University College London Medical School, London; Louise Marston, PhD, Department of Primary Care and Population Health, University College London Medical School, Royal Free Campus, London; Sally McManus, MSC, National Centre for Social Research, London; Terry Brugha, MD, FRCPsych, Howard Meltzer, PhD, Academic Unit of Social and Epidemiological Psychiatry, Department of Health Sciences, University of Leicester, Leicester; Paul Bebbington, PhD, FRCP, of Health Sciences, University of Leicester, Leicester; Paul Bebbington, PhD, FRCP,
FRCPsych, Unit of Mental Health Sciences, Faculty of Brain Sciences, University College London Medical School, London, UK

Correspondence: Michael King, Unit of Mental Health Sciences, Faculty of Brain Sciences, University College London Medical School, Charles Bell House, 67-73 Riding House Street, London W1W 7EH, UK. Email: michael.king@ucl.ac.uk

First received 16 Mar 2012, final revision 17 July 2012, accepted 17 Aug 2012

\section{References}

1 Wong YJ, Rew L, Slaikeu KD. A systematic review of recent research on adolescent religiosity/spirituality and mental health. Issues Ment Health Nurs 2006; 27: 161-83.

2 Koenig HK, McCullough ME, Larson DB. Handbook of Religion and Health. Oxford University Press, 2001. 
3 Johnstone B, Franklin KL, Yoon DP, Burris J, Shigaki C. Relationships among religiousness, spirituality, and health for individuals with stroke. J Clin Psychol Med Settings 2008; 15: 308-13.

4 Smith TB, McCullough ME, Poll J. Religiousness and depression: evidence for a main effect and the moderating influence of stressful life events. Psycho Bull 2003; 129: 614-36.

5 Koenig HG. Concerns about measuring "spirituality" in research. J Nerv Ment Dis 2008; 196: 349-55

6 King MB, Dein S. The spiritual variable in psychiatric research. Psychol Med 1998; 28: 1259-62.

7 King M, Speck P, Thomas A. Spiritual and religious beliefs in acute illness is this a feasible area for study? Soc Sci Med 1994; 38: 631-6.

8 King $M$, Speck $P$, Thomas $A$. The effect of spiritual beliefs on outcome from illness. Soc Sci Med 1999; 48: 1291-9.

9 King M, Weich S, Nazroo J, Blizard R. Religion, mental health and ethnicity. EMPIRIC - a national survey of England. J Ment Health 2006; 15: 153-62.

10 McManus S, Meltzer H, Brugha T, Bebbington P, Jennings R. Adult Psychiatric Morbidity in England 2007. Results of a Household Survey. The NHS Information Centre for Health and Social Care, 2009.

11 Kish L. Survey Sampling. Wiley, 1965.

12 King $M$, Speck P, Thomas A. The Royal Free Interview for Religious and Spiritual Beliefs: development and standardization. Psychol Med 1995; 25: 1125-34.

13 King $M$, Speck $P$, Thomas A. The Royal Free Interview for Spiritual and Religious Beliefs: development and validation of a self-report version. Psychol Med 2001; 31: 1015-23.

14 Goldberg DP, Cooper B, Eastwood MR, Kedward HB, Shepherd M. A standardized psychiatric interview for use in community surveys. Br J Prev Soc Med 1970; 24: 18-23.

15 Lewis G, Pelosi AJ, Araya R, Dunn G. Measuring psychiatric disorder in the community: a standardized assessment for use by lay interviewers. Psychol Med 1992; 22: 465-86.

16 World Health Organization. The ICD-10 Classification of Mental and Behavioural Disorders: Clinical Descriptions and Diagnostic Guidelines. WHO, 1992.

17 Meltzer H, Gill B, Petticrew M. OPCS Surveys of Psychiatric Morbidity in Great Britain. Report No 1. The Prevalence of Psychiatric Morbidity among Adults aged 16-64 Living in Private Households in Great Britain. HMSO, 1995.

18 Bebbington $\mathrm{P}$, Nayani T. The psychosis screening questionnaire. Int J Meth in Psychiatr Res 1995; 5: 11-9.

19 Stansfeld S, Marmot M. Deriving a survey measure of social support: the reliability and validity of the Close Persons Questionnaire. Soc Sci Med 1992; 35: 1027-35.

20 Barbor TF, de la Fuente JR, Saunders J, Grant M. The Alcohol Use Disorders Identification Test: Guidelines for the Use in Primary Health Care. World Health Organization, 1989.
21 Coulton S, Drummond C, James D, Godfrey C, Bland JM, Parrott S, et al. Opportunistic screening for alcohol use disorders in primary care: comparative study. BMJ 2006; 332: 511-7.

22 Walters JTR, Bisson, Jl, Shepherd, JP. Predicting post-traumatic stress disorder: validation of the Trauma Screening Questionnaire in victims of assault. Psychol Med 2007; 37: 143-50.

23 Morgan JF, Reid F, Lacey JH. The SCOFF questionnaire: assessment of a new screening tool for eating disorders. BMJ 1999; 319: 1467-8.

24 American Psychiatric Association. Diagnostic and Statistical Manual of Mental Disorder (4th edn) (DSM-IV). APA, 1994.

25 Malgady RG, Rogler LH, Tryon WW. Issues of validity in the Diagnostic Interview Schedule. J Psychiatr Res 1992; 26: 59-67.

26 Ferraro KF, Koch JR. Religion and health among black and white adults: examining social support and consolation. J Sci Study Relig 1994; 33: 362-75.

27 George LK, Larson DB, Koenig HG, McCollough ME. Spirituality and health: what we know, what we need to know. J Soc Clin Psychology 2000; 19: 102-16.

28 Michalak L, Trocki K, Bond J. Religion and alcohol in the U.S. National Alcohol Survey: how important is religion for abstention and drinking? Drug Alcohol Depend 2007; 87: 268-80.

29 Hope $\mathrm{LC}$, Cook $\mathrm{CCH}$. The role of Christian commitment in predicting drug use amongst church affiliated young people. Ment Health Relig Cult 2001; 4: 109-17.

30 Koenig HG. Handbook of Religion and Mental Health. Academic Press, 1998.

31 Lewis CA, Maltby J, Day L. Religious orientation, religious coping and happiness among UK adults. Pers Individ Dif 2005; 38: 1193-202.

32 King $\mathrm{M}$, Koeing $\mathrm{H}$. Conceptualising spirituality for medical research and health service provision. BMC Health Serv Res 2009; 9: 116

33 Pargament Kl. Psychology of Religion and Coping. Theory, Research and Practice. Guilford Press, 1997.

34 Galen LW. Profile of the godless. Results of a survey of the nonreligious. Free Inq 2009; 29: 41-5.

35 Maltby J, Day L. Spiritual involvement and belief: the relationship between spirituality and Eysenck's personality dimensions. Pers Individ Dif 2001; 30 187-92.

36 Bhui K, King M, Dein S, O'Connor W. Ethnicity and religious coping with mental distress. Ment Health 2008; 17: 141-51.

37 Taylor, H. Harris Poll: The Religious and Other Beliefs of Americans 2003. Harris Interactive, 2003 (http://www.harrisinteractive.com/vault/HarrisInteractive-Poll-Research-The-Religious-and-Other-Beliefs-of-Americans2003-2003-02.pdf).

38 Ashworth J, Farthing I. Churchgoing in the UK. 2007. Tearfund, 2007.

39 ICM Research. What the world thinks of God. BBC News Channel 2004; 26 February (http://news.bbc.co.uk/1/hi/programmes/wtwtgod/ 3518375.stm)

TA EXTRA 